\title{
STAPHYLOCOCCAL INFECTION IN HOSPITALS
}

\author{
By G. H. JANTET, M.B., F.R.C.S. \\ Lecturer in Surgery, Surgical Professorial Unit, St. Thomas's Hospital Medical School, London
}

Staphylococcal disease has been plaguing in recent years every hospital and, until the problem is fully realized and active measures taken to combat it, it will go on causing much unnecessary morbidity and even mortality.

\section{Is There a Problem?}

Some still deny that there is a problem, but, as Ravenholt and La Veck (1956) point out, - Staphylococcal disease is a major problem in the better hospitals with good laboratories and a hospital infection record-keeping system, and hospitals without such laboratories or system usually state that they have no staphylococcal disease problem.' Godfrey and Smith (1958) doing a 'hospital round ' found that I I.I per cent. of 634 in-patients had a staphylococcal infection.

The common hospital staphylococcal diseases are:-

Wound infections-including surgical and traumatic wounds, intravenous therapy wounds and the 'wounds' of catheterization.

Skin infections and conjunctivitis in adults, infants and hospital personnel.

Mastitis in lactating breasts.

Pneumonia.

Enterocolitis.

Urinary infections.

To this list the carrier-state should probably be added, whether the staphylococcus is carried in the nose or elsewhere on the body.

The problem is very real: every person coming in contact with hospitals is at risk and every department is affected-the surgical, maternity and infant departments have received most publicity but the medical departments are not exempt, as debilitated or old patients seem particularly prone to superimposed staphylococcal infection such as pneumonia which may well prove fatal-the causal organism probably not being suspected unless it is looked for.

Godfrey and Smith (1958) examined the records of 534 autopsies in one year and found that 20 patients (4 per cent.) had died from staphylococcal disease, 69 (I4 per cent.) had 'severe staphylococcal disease contributing to death,' and 70 (14 per cent.) grew coagulasepositive staphylococci pyogenes from various tissues (the blood and respiratory tract being the commonest). Robertson (1958) reported from Canada 178 wound infections in 1,917 cases (9.3 per cent.), of which 46 (2.4 per cent.) were 'significant ' infections; staphylococci were present in over one-third of all infected wounds and in four-fifths of ' significant' infections. Dineen and Pearce (1958) in a ro-year study from New York found the surprisingly low wound-infection rate of 5 I I out of 52,022 operations, with an annual average of 1.0 per cent., of which, however, 0.6 per cent. were due to staphylococci. Shooter et al. (1958), reporting an eight months survey from London, found that 17 out of $3 I_{1}$ surgical patients (5.5 per cent.) developed a staphylococcal infection (wound infection, pneumonia, enterocolitis or G.U. tract infection). The infection rate of wounds generally has been the subject of many papers recently and seems to vary between 5 and 14 per cent., but care should be taken in comparing different series as the criteria usually differ. (Clarke, 1957; W. Burnett et al., r958; W. E. Burnett et al., 1958; Jeffrey and Sklaroff, 1958; Shooter et al., 1956; Kinmonth et al., 1958; Caswell et al., 1958.)

Wysham and Kirby (1957) showed that staphylococci were infecting patients throughout the hospital and found that during a three and a half months period 4 per cent. of all in-patients had a staphylococcal infection.

In the maternity and infant departments the problem is even more serious: Gillepsie et al. (1958) found that II.8 per cent. of infants in a Bristol maternity hospital had a staphylococcal disease; Ravenholt et al. (1957), reporting on 15 Seattle hospitals and 714 families, found that 4 per cent. of the mothers who attempted to feed their babies developed staphylococcal mastitis and I 8 per cent. of the babies developed staphylococcal skin sepsis- 5 of the 4 r babies born during one 
month in one of the hospitals dying of staphylococcal disease. Timbury et al. (1958) recently reported a staphylococcal epidemic in a Glasgow maternity hospital which killed 8 babies in the six and a half weeks before the hospital was closed.

The staphylococcal problem has already spread outside the hospitals. Wysham and Kirby (1957), reporting from the U.S.A. on 189 patients with staphylococcal disease during a period of three and a half months, found that 100 had developed their infection during their stay in the hospital, 32 within 60 days of discharge from the hospital, and 57 had come into hospital already with staphylococcal disease: in all there were 24 deaths for which the staphylococcus was either directly responsible or a contributory cause; he showed that patients were carrying the hospital staphylococcus outside the hospital and were thus spreading it.

\section{How Did the Problem Arise?}

In the pre-Pasteur days, infection was an accepted and inevitable risk associated with hospital treatment. With the discoveries of Pasteur and the work of Lister, hospitals were made safer for patients, and surgery in particular was able to take great steps forward. When some 20 years ago chemotherapeutic and antibiotic agents were brought in, the control of infections seemed at hand. This proved to be so for many infections, and an inevitable slackness in strict aseptic and cross-infection precautions unfortunately crept in, more and more reliance being placed on antibiotics, whose range seemed limitless.

However, it soon became apparent that staphylococcal infections were becoming progressively more resistant to antibiotics and were rapidly replacing other infections, which had remained sensitive, as the major type of infection in hospitals; so that, if present trends are maintained, the hospital staphylococcus will soon become an all-antibiotic-resistant organism. In Wysham and Kirby's (1957) analysis of 189 patients with staphylococcal disease, over 20 per cent. had organisms sensitive to bacitracin only, whereas in I955 bacitracin-resistant staphylococci were virtually unknown. Furthermore, the characteristics of the emerging hospital staphylococcus seem to be different from the preantibiotic staphylococcus, so that the origin of the present problem is tied up with this and the uses of antibiotics (which will be discussed later).

\section{The Hospital Staphylococcus}

It is thought that the antibiotic-resistant hospital staphylococcus has arisen mainly because the more sensitive strains have been kept in abeyance by antibiotics allowing the resistan strains to emerge, but Barber (1957) has shown that long-continued exposure of staphylococci to minute doses of penicillin may produce penicillin resistant strains, so that they may have arisen this way as well. Gould (1958) gives evidence t⿳亠丷厂巾 suggest that penicillin is present in hospital air im sufficient concentration to knock out the sensitivo strains; this may also perhaps induce mutation to the resistant strains as suggested by Barbee Clarke et al. (1952) and Gillepsie et al. (1958) have shown that staphylococcal resistance to antie biotics occurs in proportion to the amount the antibiotic is used.

Hospital staphylococcal disease can be endemi or epidemic. Endemic infections seem to be caused by a multiplicity of different phage-types 3 . Shooter et al. (1958) isolated 186 different phageș types in a surgical ward, 13 of which were responsible for disease. Severe epidemic infecor tions, however, appear to be due mostly to phages types 80 and $8 \mathrm{I}$, and although first described in Australia by Rowntree and Freeman (1955) the have now spread very widely and have been reported in New Zealand, Canada, the U.S.A. ant this country-Wise (1958); W. E. Burnett et at. (1958); Timbury et al. (1958); Shooter (1958) $\vec{\phi}$ Shooter et al. (1958); Caswell et al. (1958). 응

Although there exists at the moment no simple test of the virulence of staphylococci, accumulat evidence suggests very strongly that the antibiotic $\stackrel{3}{-}$ resistant staphylococci (i.e. the hospital staphye lococci) are more virulent than the antibioticio sensitive ones (Shooter, 1958; Editorial Brito med. F., 1958; Lancet, 1958; Shooter et al., 1958) This evidence is based largely on the observation that the severe cases, or the severe outbreaks, are almost always associated with the antibiotic - resistant staphylococci. Wysham and Kirb (1957), in their analysis of 189 patients men:tioned above, found that of the roo patients in the first group who developed their infection while ii hospital, only 3 per cent. had staphylococc 종 sensitive to all antibiotics, but 86 per cent. ha staphylococci resistant to two or more antibiotic of which 26 per cent. were sensitive to bacitracio only; in this group 21 patients died (staphylococc i being the cause or contributing), of which 12 werer from the 26 per cent. whose staphylococci were sensitive to bacitracin only; the infections in thid group were all severe- - severe wound infections pneumonias, septicaemias and skin infections (if infants). On the other hand, of the 57 patients io the second group, who came into hospital with $\underset{80}{8}$ staphylococcal infection-presumably acquired outside the hospital -40 per cent. had staphy ${ }^{\circ}$ lococci sensitive to all antibiotics, 35 per cent. ha席 staphylococci resistant to penicillin only and ig pe 
cent. had staphylococci resistant to two or more antibiotics, but in several of these latter, members of the family had recently been hospitalized; furthermore, in this second group the infections were mostly mild skin infections and there were no deaths.

This very interesting analysis shows that hospital staphylococci are mostly antibioticresistant, while outside hospitals they are still mostly sensitive although some spread outside has already occurred; it shows, also, that the more severe infections are associated with the resistant hospital staphylococci which are also responsible for more deaths.

These findings illustrate the increased virulence of hospital staphylococci. The danger is twofold: firstly from their greater virulence and secondly from the fact that antibiotics are only of limited value against them.

Thus the wholesale use of the antibiotics has produced strains of antibiotic-resistant staphylococci which are infecting hospitals far and wide and causing much concern because of their virulence.

\section{Source and Spread}

Most authors agree that the main source of the organism is the infected case and that direct contact is of primary importance in spread of the disease (W. E. Burnett et al., 1958; Kinmonth et al., 1958; Wise, 1958; Caswell et al., 1958; Wysham and Kirby, I957; Langmuir, 1958; Hare and Ridley, 1958; Gillepsie et al., r958). The part played by vectors such as clothing, bedding and bedscreens which are not sterilized between patients is also becoming appreciated (Lancet, r959).

Caswell et al. (1958) and W. E. Burnett et al. (1958) found, as evidence of the importance of direct contact, that staphylococcal skin infections in hospital staff were only on parts coming in contact with patients (arms, hands, face) from which the infection was transferred to other patients. Gillepsie et al. (1958) also found that measures aimed at reducing direct spread were the most effective in reducing the sepsis rate in infants in a maternity hospital. These authors do not think that air-borne spread plays a very large part in cross-infection in the wards but it is difficult to accept this view in, for example, the epidemiology of staphylococcal pneumonia in medical wards. Shooter et al. (I956), however, have proved the importance of this route in operating-theatre-acquired infections: they were able to reduce their wound-infection rate from 9 to I per cent. when theatre ventilation was altered so that contaminated air from the wards no longer reached the theatre.

The role of carriers in the spread of hospital staphylococcal infections is very much under discussion. It has been assumed, perhaps a little too readily, that nasal staphylococcal carriers were responsible for spreading much of the disease, and for that reason the hospital staff itself has often been blamed, as its nasal carriage rate of hospital staphylococci is high: it has been variously reported as 34 per cent. by Loh and Street (1957), 4I per cent. by W. E. Burnett et al. (1958), and 50 per cent. by Wise (1958), the latter also noticing that when the number of carriers decreased, the number of hospital-acquired staphylococcal infections did so as well. On the other hand, Caswell et al. (1958) found that epidemics were related more to the number of hospital personnel with active infections with the responsible staphylococcus than to the number of nasal carriers of the same staphylococcus.

W. E. Burnett et al. (1958), who found a 4I per cent. nasal carriage rate, found that only 4 per cent. were nasal carriers of the phage types 80 and $8 \mathrm{r}$ which were responsible for 69 per cent. of their hospital infections. Timbury et al. (1958), reporting a phage-type 80 epidemic, found a low nasal carriage rate among staff. These findings suggest that the part played by nasal carriers may have been overstressed. Hare and Ridley (1958) have found, however, that staphylococci may be carried on sites other than the nose (hands, perineum, arms, face, etc.) and also that some carriers disperse their organisms around them while others do not, so that, as pointed out by Kinmonth et al. (1958), the number of carrier-dispersers of dangerous staphylococci is possibly of more importance than the nasal carrier rate-but unfortunately no test of virulence exists which would help to distinguish all the potentially dangerous staphylococci.

One further factor facilitating spread lies in the hardy character of the staphylococcus itself: it can survive the most adverse conditions of drying, so that once shed by a patient or carrier it might retain its virulence for a long time (Robertson, 1958).

\section{Control of the Problem}

Antibiotics are here to stay (their banning, in turn, and re-introduction under stricter control does not, unfortunately, seem realizable) and, therefore, antibiotic-resistant staphylococci must also be here to stay.

Nevertheless hospitals must be made safer for patients: this can be done, as hospital staphylococcal infections are largely preventable. The methods of prevention will be briefly outlined. 


\section{Stricter Criteria for the Administration of Antibiotics}

Antibiotics being at the source of the problem, the indications for their use must be made stricter than they now seem to be. The use of antibiotics in prophylaxis is controversial. Petersdorf et al. (I957) found them to be of no benefit and, in fact, distinctly hazardous in unconscious patients in preventing chest complications or urinary infections (if catheterized). Godfrey and Smith (1958) similarly found that many of those on prophylactic antibiotics nevertheless developed staphylococcal infections. Prophylactic antibiotics post-operatively are discussed by Wysham and Kirby (1957), who think they will only favour the emergence of resistant strains.

Their use as the sole measure of treatment in infections of wounds, lymph nodes, bone, etc., can only be justifiable in the early cellulitic stage before pus has formed, after which they cannot be expected to reach the abscess cavity-many collections of pus are masked in this way. The best treatment when pus is present is wide drainage and not antibiotics; the latter can be used in conjunction with drainage if there is a spreading infection -but the sensitivity of the organism to the proposed antibiotics should first be determined if possible. Local applications of antibiotics, quite apart from sensitization dangers, only favour the emergence of resistant strains.

\section{A Return to Stricter Aseptic Techniques}

As mentioned above, the ' antibiotic umbrella' has led to a relaxation of aseptic precautions which has consequently opened the door to infections by antibiotic-resistant staphylococci. From the surgical point of view this is, therefore, largely preventable by insisting on stricter measures of asepsis. All authors agree on this point and emphasize particularly proper pre-operative skin preparation, a return to the ro-minute scrub of the surgeon's hands and forearms with a brush, a complete change of clothing for the operatingtheatre team, the banning of beds, blankets, etc., in the operating theatre and a careful aseptic technique for the dressing of wounds in the wards (Robertson, 1958; Caswell et al., 1958; W. E. Burnett et al., 1958). The dangers of incorrect ventilation of operating theatres has already been mentioned (Shooter et al., 1956).

\section{Prevention of Cross-infection}

The two most important control measures in this field are isolation of the infected case (if this is not realizable, barrier nursing should be instituted) and frequent hand washing, since direct spread by contact is so important. Ideally these measures should be associated with steriliza- ̊ tion of bedding, curtains, screens, etc., between $z$ patients, and a review in each hospital of all $\stackrel{\unrhd}{\not}$ possible sources of cross-infection such as baths,.. thermometers, crockery, anaesthetic apparatus, $\underset{\vec{D}}{\vec{\rho}}$ ward oxygen inhalation sets, etc. Hospitals $\frac{9}{0}$ struck by severe epidemics may even require to be $\frac{0}{0}$ closed for a time and disinfected as described by $\frac{\bar{D}}{\bar{D}}$ Timbury et al. (1958).

\section{The Problem of Carriers}

It is clearly impossible to remove from hospitals $\overrightarrow{0}$ all coagulase-positive staphylococcal carriers, as $\overrightarrow{\vec{H}}$ their numbers are so large and their role in the spread of the disease far from definite. Treating $\vec{D}$ them all is also probably valueless, since so many 3 seem to become carriers again as soon as treatment is stopped and they return to the wards. Nevertheless it is wise to remove from duty, and treat, all carriers of known virulent staphylococci (such as phage-types 8o/8I). More work is required on $\stackrel{N}{-}$ this aspect, particularly on the role played by 은 staphylococcal dispersers (Hare and Ridley, 1958).

Brodie et al. (1956) found that the nasal carriage $\subseteq$ rate among patients rose from 20 to 38 per cent. after one week in hospital, but carriage rates in $\overrightarrow{0}$ other sites was not measured; however, Kinmont et al. (1958) found that ro per cent. of the patients were skin carriers of the hospital staphys lococcus at operation; these findings seem to confirm the opinion that the length of stay of patients in hospital before operation should be $\stackrel{\circ}{\mathbb{Q}}$ kept down to the strict minimum in order to reduce wound sepsis.

\section{Other Measures}

A system for recording and investigating all hospital infections should be established and instruction on the present problem given to all hospital personnel (medical, nursing and domestic). That these control measures can be effective is shown by the diminution in clean wound infection rates obtained by various authors: 5 per cent. to $0.4^{-1}$ per cent. (W. E. Burnett et al., 1958), 5 per cent. to $0.8-1.5$ per cent. (Caswell et al., r958), 9 per cent. to I per cent. (Shooter et al., r956), to about one-third of previous value (Robertson, or r958), and by the diminution in number of $N$ staphylococcal infections in infants from 5.2 per cent. to 2 per cent. obtained by Gillepsie et al. (1958).

\section{Conclusions and Summary}

The reality of staphylococcal infections in $\frac{T}{O}$ hospitals as a present-day problem has been emphasized.

Large-scale use and misuse of antibiotics, 
associated with a relaxation in aseptic techniques, is responsible for the emergence of and infections with, the 'Hospital Staphylococcus': an antibiotic-resistant strain, apparently more virulent than its predecessors, liable to cause large-scale epidemics, extremely well adapted for cross-infection by its ability to survive the most adverse conditions and particularly liable to produce a carrier-state. Its exact mode of spread is still obscure but direct contact plays an important part. A hospital staphylococcal infection carries the twofold danger of virulence and antibiotic resistance. For this reason the problem is now as serious as it was in the pre-antibiotic era, with other virulent organisms now replaced by the hospital staphylococcus. The problem is largely preventable by strict control measures aimed at limiting the use of antibiotics, and a return to strict aseptic and cross-infection precautions. The infected "case must be considered as a real source of danger to himself and to others.

\section{Acknowledgment}

I' should like to thank Professor J. B. Kinmonth for kindly reading this paper and making helpful criticisms.

\section{BIBLIOGRAPHY}

Annotation (1958), Lancet, 11, 1110.

Annotation (1959), Ibid., i, 34 .

BARBER, M. (1957), in 'Drug Resistance in Micro-organisms,' edited by G. W. Wolstenholme and C. M. O'Connor, London.

BRODIE, J., KERR, M. R., and SOMMERVILLE, T. (1956), Lancet, i, ig.

BURNETT, W., MCDONALD, S., and TIMBURY, M. C. (1958), Scot. med. F., 3, 392.
BURNETT, W. E., CASWELL, H. T., SCHREK, K. M., CARRINGTON, E. R., LEARNER, N., STEEL, H. H., TYSON, R. R., and WRIG̈HT, W. C. (1958), F. Amer. med. Ass., 166, 1183 .

CASWELL, H. T., SCHREK, K. M., BURNETT, W. E. CARRINGTON, E. R., LEARNER, N., STEEL, H. H., TYSON, R. R., and WRIGHT, W. C. (1958), Surg. Gynec. Obstet., I06, 1 .

CLARKE, S., DALGLEISH, P. G., and GILLEPSIE, W. A. (1952), Lancet, i, II 32 .

CLARKE, S. K. R. (1957), Brit. F. Surg., 44, 592.

DINEEN, P., and PEARCE, C. (1958), Surg. Gynec. Obstet. I06, 453.

Editorial (1958), Brit. med. F., i, 207.

Editorial (1958), Lancet, i, 515.

GILLEPSIE, W. A., SIMPSON, K., and TOZER, R. (1958), Ibid., ii, 1075 .

GODFREY, M. E., and SMITH, I. M. (1958), f. Amer. med. Ass., 166, 1197.

GOULD, J. C. (1958), Lancet, i, 489.

HARE, R., and RIDLEY, M. (1958), Brit. med. F., i, 69.

JEFFREY, J. S., and SKLAROFF, S. A. (1958), Lancet, i, 365.

KINMONTH, J. B., HARE, R., TRACY, G. D., THOMAS, C. G. A., MARSH, J. D., and JANTET, G. H. (1958), Brit. med. f., 2, 407.

LANGMUIR, A. D. (1958), f. Amer. med. Ass., 166, 1202.

Leading Article (1958), Lancet, i, 250.

Leading Article (1958), Ibid., ii, 1 106.

LOH, W. P., and STREET, R. B. (1957), New Engl. F. Med., 256, 177 .

PETERSDORF, R. G., CURTIN, J. A., HOEPRICK, P. D., PEELER, R. N., and BENNET'T, I. L.' (I957), Ibid., 257, I00I.'

RAVENHOLT, R. T., and LA VECK, G. D. (1956), Amer. $\mathcal{F}$. Publ. Hlth, 46, 1287 .

RAVENHOLT, R. T., WRIGHT, P., and MULHERN, $M$. (1957), New Engl. भै. Med., 257, 789.

ROBERTSON, H. R. (1958), Ann. Roy. Coll. Surg., 23, 141.

ROWNTREE, P. M., and FREEMAN, B. M. (1955), Med.F. Aust., 2, 157.

SHOOTER, R. A. (1958), Ann. Roy. Coll. Surg., 23, 312.

SHOOTER, R. A., SMITH, M. A., GRIFFITHS, J. D., BROWN M. E. A., WILLIAMS, R.' E. O., RIPPON, J. E., and JEVANS, M. P. (1958), Brit. med. $\ddot{\mathcal{F}}$., i, 607 .

SHOOTER, R. A., TAYLOR, G. W., ELLIS, G., and ROSS, J. P. (1956), Surg. Gynec. Obstet., 103, 257.

TIMBURY, M. C., WILSON, T. S., HUTCHISON, J. G. P., and GOVAN, A. D. T. (1958), Lancet, it, r081.

WISE, R. I. (1958), F. Amer. med. Ass., 166, 1178.

WYSHAM, D. N., and KIRBY, W. M. (1957), Ibid., 164, 1733.

References continued from page 412-H. Harold Friedman, M.D. Thomas G. Argyros, M.D., and Otto Stienbrocker, M.D.

14. NAFFZIGER, H. C., and GRANT, W. T. (1938): 'Neuritis of the brachial plexus, mechanical in origin: the scalenus syndrome,' Surg. Gynec. Obstet., 67, 722.

15. OCHSNER, A., GAGE, M., and DEBAKEY, M. (1935): 'Scalenus anticus (Naffziger) syndrome,' Amer. F. Surg.,

16. PAULL, R. (1946): 'The neurovascular syndrome as manifested in the upper extremities, Amer. Heart $\mathcal{F}_{\text {., } 32,32 .}$

17. PEET, R., HENRIKSEN, J. D., and ANDERSON, M. G. M. (I956):' Thoracic outlet syndrome: evaluation of a therapeutic exercise programme,' Staff Meet. Mayo Clin., May 2.

18. RAAF, J. (1955): 'Surgery for cervical rib and scalenus anticus syndrome,' $\mathcal{Y}$.A.M.A., 157, $219-223$.

19. STAMMERS, F. A. R. (1950): 'Pain in the upper limb from mechanisms in the costoclavicular space,' Lancet, April $x$.

20. STEINBROCKER, O., SPITZER, N., and FRIEDMAN, H. H. (1948): " The shoulder-hand syndrome in reflex dystrophy of the upper extremity,'Ann. intern. Med., 29, 22.

21. STEINBROCKER, O., and ARGYROS, T. G. (1958): 'The shoulder-hand syndrome: Present status as a diagnostic and therapeutic entity,' Med. Clin. N. Amer., November.
22. STEINBROCKER, O., NEUSTADT, D., and BOSCH, $S$. (1955): 'Painful shoulder syndromes; their diagnosis and treatment,' Ibid., 39, No. 2, 1 .

23. TELFORD, E. D., and MOTTERSHEAD, S. (1947): 'The "costoclavicular syndrome," Brit. med. $\dot{F}$., 1, 325-328, March 15.

24. THEIS, F. V. (1939): 'Scalenus anticus syndrome and cervical ribs,' Surgery, 6, No. I, $112-125$.

25. COOTE and LAW, cited in UPMALIS, I. H. (1958): ' The scalenus anticus and related syndromes,' Surg. Gynec. Obstet. with Int. Abstr. Surg., 107, No. 6, December.

26. WALSHE, F. M. R. (1951): 'Nervous and vascular pressure syndromes of the thoracic inlet and cervico-axillary canal. 'Modern Trends in Neurology,' p. 542. Edited by A. Feiling. Butterworth, London.

27. WILLSHIRE ( 1860 ): Referred to in clinical records, 'Supernumerary first rib,' Lancet, ii, 633 .

28. WRIGHT, I. S. (1945): 'The neurovascular syndrome produced by hyperabduction of the arms,' Amer. Heart $\mathcal{F}$., 29, I. 